\title{
ECONOMIC INCENTIVES IN SUSTAINABLE WATER MANAGEMENT: A RISK - BASED DECISION ANALYSIS APPROACH FOR DETERMINING GROUNDWATER POLLUTION CHARGES UNDER UNCERTAINTY
}

\author{
Y. A. MYLOPOULOS ${ }^{*}$ \\ N. A. MYLOPOULOS2
}

\author{
1 Division of Hydraulics \& Environmental \\ Engineering - Department of Civil Engineering \\ Aristotle University of Thessaloniki \\ GR -540 06 Thessaloniki, Greece \\ 2Department of Civil Engineering - University of Thessaly \\ GR -383 34 Volos, Greece
}

Received: 05/05/99

Accepted: 01/09/99

*to whom all correspondence should be addressed

fax: + (30) 31-995-658

e-mail:mylop@civil.auth.gr

\begin{abstract}
A risk-based decision analysis methodology is presented, that can be used as a water policy tool in the design of economic incentive instruments, under conditions of uncertainty. A contaminated groundwater resource system with unknown hydrogeological parameters is used as a case study. The polluter has to select the policy to be followed among a series of alternatives, ranging from the extreme and environmentally risky scenario of paying pollution charges as long as the aquifer will remain polluted, up to the conservative option in terms of reduced environmental risks policy of safely rehabilitating the groundwater system. The full-cost price of water, including direct, opportunity, and environmental costs, both actual and probabilistic, as well as the risks of failure of the alternative scenarios due to the uncertainty, as they result from stochastic simulation, are embedded in a risk-cost-benefit decision model, developed for the evaluation of the alternatives. The pollution charges to be imposed by the local water authority are determined through the appropriate development of this model and the use of a proposed algorithm, in a way that these charges can act as incentives to the polluters, forcing them, or the authorities, to select the most environmentally sustainable water policy, namely that of safely restoring the aquifer.
\end{abstract}

KEY-WORDS: Sustainable Water Resources Management, Economic Incentives, Full-Cost Pricing of Water, Risk-Based Decision Analysis, Pollution Charges, Groundwater Remediation

\section{INTRODUCTION}

\section{Integrating Environment and the Economy}

It is widely accepted today that protection of the environment and economic development are not separate challenges. Development cannot exist in a deteriorating environmental resource base, and the environment cannot be protected and enhanced when growth plans consistently fail to consider the full cost of environmental destruction. It is clear in our days that most of our environmental problems are translated as "negative 
externalities" of an economic system, which takes for granted - and thus undervalues - many aspects of the environment. The integration of environmental and socio-economic issues is a key requirement in the concept of sustainability, not only for the protection of the environment, but also for the promotion of a long-term economic development (World Commission on Environment and Development, 1987).

Assessing the economic importance, looking for the economic causes, and designing economic incentives to slow, halt and reverse environmental degradation, are among the first priorities of the environmental economics, and among the basic elements of an environmental policy that can guarantee long-term environmental and economic sustainability (Sarokin and Schulkin, 1993).

\section{Managing Water as an Economic Resource}

Water is but one example of natural resources that goes largely unpriced today. Failure to recognize the economic nature of water, which means regarding water as a completely free, renewable resource, has contributed to inefficient allocation and to wasteful and environmentally damaging uses. Managing water as an economic resource, through the recognition of its full economic value, as well as through the use of economic incentive instruments, is among the key characteristics of a sustainable water policy (Winpenny, 1994; JonchClausen, 1994; Mylopoulos Y. and Kolokytha, 1996; Mylopoulos Y., 1996).

Full-cost pricing in the case of water involves all of the following types of costs:

1. Direct costs in form of capital, labor and institutional arrangements,

2. Opportunity costs reflecting the most valuable alternative use of water, and

3. Environmental costs, in terms of benefits foregone and long-term consequences by polluting or depleting the water system.

While the above-presented key concepts of sustainable water management are widely accepted, their implementation in the real world seems to meet a lot of obstacles. Political and administrative shortcomings, particular economic and social conditions, as well as the lack of the socalled previous experience, make the integration of the environment and the economy, a rather frustrating issue today.

\section{Making Decisions under Uncertainty. Risk-Based Decision Analysis}

Merging environmental and economic issues becomes however an even more complex task, in cases where the uncertainties associated with the heterogeneity and/or the lack of data and information of environmental systems, have impacts on the economic analysis, playing therefore an important role in policy design. These are the cases where uncertainties as to basic parameters of the environmental systems affect the design policies, so that the potential risks of failure become a critical parameter in the awkward economic analysis. In these cases, the decision-making process has to quantify and to take into account, in addition to the actual costs and benefits, the risks associated with the decision-making process, reflecting the probabilistic costs of failure of alternative policies. The probability of failure, resulting from stochastic simulation of environmental systems under study, becomes then a critical component in the design. The traditional economic analysis based on a Cost-Benefit evaluation of the alternative schemes is replaced in these cases by the Risk-Based Decision Analysis, in which both actual and probabilistic costs emerging from the environmental uncertainties, are taken into account and evaluated (Massmann and Freeze, 1987a,b; Covello, 1987; Freeze et al., 1990; Massmann et al., 1991; Mylopoulos Y. et al., 1994; Latinopoulos et al., 1997).

\section{The present work}

This work deals with the development of a risk-based decision analysis framework, which can be used as a water pricing tool in the design of economic incentive instruments, under conditions of uncertainty.

A contaminated groundwater system, in which the heterogeneous and more or less unknown hydrogeologic environment results to a high degree of uncertainty, will be used as a case study for the development of the methodology. The polluter has to evaluate on a risk basis a series of alternatives: from the extreme and environmentally risky scenario of "doing nothing" for the restoration of the aquifer, having high environmental costs due to the pollution charges, up to 
the conservative policy of safely rehabilitating the groundwater system. The latter is characterized as conservative, in terms of reduced environmental risks, as it concerns a solution with high direct and low opportunity and environmental costs.

The local water authority, aiming at imposing a sustainable water policy in the aquifer, has to design its economic policy in a way, that will make attractive to the polluters the most environmentally friendly alternative, namely that of restoring the aquifer. Pollution charges therefore have to be determined in such a way that will permit them to act as economic incentives rather than as penalties to the polluters. This can be achieved if the objective function of the decision model, including all the actual and risk costs, become maximum in the less, and minimum in the most environmentally sustainable alternative policy. The utility function of the decision model, reflecting the attitude of the various kinds of polluters versus risk, plays a critical role in the decisionmaking process, so that its study will decisively help in the development of the methodology with which the most appropriate pollution charges will be determined.

The risk-based methodology that will be developed relates water pollution charges with the full-cost price of water, both actual, and probabilistic. Pollution charges under conditions of uncertainty are then determined on a risk-costbenefit basis in such a way, that can guarantee the promotion of the less environmentally risky, and therefore more sustainable, water policy alternative. In other words, this paper can be characterized as a contribution in shifting from "the Polluter Pays" to the more sustainable "the Polluter Restores" principle.

\section{DESCRIPTION OF THE CASE STUDY The groundwater contamination accident}

A contaminated aquifer used for freshwater supply by a nearby community, serves as a case study for the development of the methodology. Due to an accident in an underground industrial pipeline, a spill of waste was released in the region 3 years ago. The waste passed after leakage through the upper geological formations of the aquifer and managed to reach the groundwater, resulting in the contaminant plume shown in Figure 1. The waste water contains a hazardous reactive organic pollutant, trichloroethylene (TCE). This pollutant is a widely used solvent, for which existing regulatory policies impose a severe safe criterion for drinking water, that corresponds to a maximum value of $5 \mu \mathrm{g} / \mathrm{l}$. The polluted water migrates due to local groundwater flow toward the supply wells A and B, threatening their water with contamination for a long time.

\section{The aquifer under study}

The aquifer under study, along with the plume of pollutants as it was detected in the groundwater, the water supply wells A and B, and the cleanup wells C, D, E and F installed in all the alternative scenarios presented below, are shown in Figure 1. The aquifer is bounded by no-flow boundaries along the left and right sides and by constant head boundaries along the top and bottom sides, with hydraulic heads equal to 22.0 and $13.4 \mathrm{~m}$, respectively. The pumping rate of each water supply well is $750 \mathrm{~m}^{3} /$ day, in order to meet the water supply demand of the nearby village, which is $1500 \mathrm{~m}^{3} /$ day.

Information about the hydrogeology of the aquifer is limited, especially as far as the spatial variability of the parameter of the hydraulic conductivity is concerned. Assuming that all other aquifer characteristics can be estimated with good approximation, using experience from other nearby similar sites, the stochastic approach is confined to hydraulic conductivity only. The values of the assumed known parameters of the aquifer are as follows: aquifer thickness $b=10 \mathrm{~m}$, effective porosity $\mathrm{n}=0.30$, longitudinal dispersivity $\mathrm{a}_{\mathrm{L}}=$ $10 \mathrm{~m}$ and transverse dispersivity $\mathrm{a}_{\mathrm{T}}=1 \mathrm{~m}$.

\section{The alternative scenarios}

The four scenarios described below represent the four characteristic alternatives available for the polluter (Table 1). As it will be shown, the alternatives range from the high environmentally risky scenario of doing nothing to restore the aquifer, up to the conservative, from the environmental point of view, strategy of the complete decontamination. All the alternatives have the common component that they must assure the continuous supply of the village with fresh water.

1. In the first strategy no remedial measures for the groundwater are designed and this is 
the reason it is called "the do nothing" alternative. This is the least environmentally friendly management scenario, as the aquifer remains contaminated for a long time, up to 35 years for some contamination episodes, as calculated by the stochastic simulation model, described below. The contaminated supply wells are assumed to be abandoned from the beginning of the problem. The water supply demand is met by constructing new water supply wells either in safe parts of the same aquifer or in other water sources. This is the least expensive strategy in terms of direct costs, as no remediation is involved. The costs however that should be taken into account in this scenario, include the opportunity costs of continuously meeting the water supply demands of the village, as well as the under study environmental costs reflecting the pollution charges that should be levied by the water authority for each year of groundwater contamination.

In the remaining 3 strategies the construction and operation of remedial plants with varying capacity and different duration is designed, in the way described below:

2. Two clean-up wells, $C$ and $D$ are installed, with remedial capacity $Q_{C}=Q_{D}=1000$ $\mathrm{m}^{3} /$ day each.

3. Three clean-up wells, C, D and E are installed, with remedial capacity $\mathrm{Q}_{\mathrm{C}}=\mathrm{Q}_{\mathrm{D}}=\mathrm{Q}_{\mathrm{E}}=875 \mathrm{~m}^{3} /$ day each.

4. Four clean-up wells, C, D, E and F are installed, having remedial capacity $\mathrm{Q}_{\mathrm{C}}=\mathrm{Q}_{\mathrm{D}}=\mathrm{Q}_{\mathrm{E}}=\mathrm{Q}_{\mathrm{F}}=750 \mathrm{~m}^{3} /$ day each.
In the above described strategies, the sites of the clean-up wells were best selected after repeated trial-and-error simulations. In addition, each remedial capacity has the maximum permissible value with respect to the hydraulic constraints imposed to keep the aquifer confined. For each strategy, two alternative operational periods of the clean-up wells are examined, corresponding to 6 and 10 years of operation, so that the total number of finally evaluated scenarios become 7 .

In addition to the direct costs reflecting construction and operation costs of the remedial plants, the environmental costs representing pollution charges for each year of aquifer contamination, as well as the costs of meeting the water supply demands of the village have to be taken into account in the last three strategies, for each year during which the water supply wells will be found to be contaminated and have to be abandoned, due to insufficient remediation measures.

\section{The Probabilities of Failure}

According to the problem description, there are two different types of risk of failure for each alternative strategy: one connected with the probabilistic environmental costs, and the water authority's policy to impose charges to the polluters for each year the groundwater is found contaminated anywhere in the aquifer; the other connected with the probabilistic opportunity costs, representing the costs of meeting water supply demands, each year that the water supplies are found contaminated. The probability distribution functions through which these two types of risks are evaluated, can be interpreted with the use of the stochastic simulation model (see Appendix), after the calculation of the two relevant types of probability of failure:

Table 1. Alternative scenarios of the decision model

\begin{tabular}{|c|c|c|c|c|}
\hline \multirow{2}{*}{ Strategy } & Key Action & \multirow{2}{*}{ Operation time } & \multicolumn{2}{|c|}{ Objective } \\
\cline { 3 - 4 } & & & $\begin{array}{c}\text { Water } \\
\text { Supply }\end{array}$ & $\begin{array}{c}\text { Deconta- } \\
\text { mination }\end{array}$ \\
\hline 1 & & & Yes & No \\
\hline 2 & "Do nothing" & 2a. 6 years & Yes & Yes \\
\hline \multirow{2}{*}{3} & 2 clean-up wells & 2b. 10 years & Yes & Yes \\
\cline { 3 - 5 } & \multirow{2}{*}{3 clean-up wells } & 3a. 6 years & Yes & Yes \\
\cline { 3 - 5 } & & 3b. 10 years & Yes & Yes \\
\hline \multirow{2}{*}{4} & 4 clean-up wells & 4a. 6 years & Yes & Yes \\
\cline { 3 - 5 } & & 4b. 10 years & Yes & Yes \\
\hline
\end{tabular}


a. The probability of failure with respect to the aquifer, $\mathrm{P}_{\mathrm{fa}}(\mathrm{t})$, reflecting the frequency of the contamination episodes anywhere in the aquifer during the specific year; contamination episodes correspond to those simulated realizations, for which the aquifer is found contaminated, and

b. the probability of failure with respect to the water supply wells, $\mathrm{P}_{\mathrm{fw}}(\mathrm{t})$, reflecting the frequency of the contamination episodes in the area of the supply wells, during this certain year: contamination episodes correspond only to those realizations for which groundwater is found contaminated in the supply wells.

Either the aquifer or the supply wells are assumed to be contaminated when the concentration of the pollutants exceeds the upper limit of $5 \mathrm{mg} / \mathrm{l}$. Health damages or cost of lives are not taken into account at all, as it is assumed that an emergency system can effectively protect the village from undesirable consequences.

\section{RESULTS AND DISCUSSION}

In the present case study, the actual and probabilistic costs presented above take the following values:

The capital cost of constructing a pumping well, $\mathrm{C}_{\text {jcap }}(\mathrm{t})$, (see Appendix), is estimated in the first year as follows:

$$
\begin{aligned}
& \$ 48,000 \text { for } Q=750 \mathrm{~m}^{3} \\
& \$ 52,000 \text { for } Q=875 \mathrm{~m}^{3} \\
& \$ 56,000 \text { for } Q=1000 \mathrm{~m}^{3}
\end{aligned}
$$

The actual annual operation costs of the clean-up wells are defined as $\$ 22 / 1000 \mathrm{~m}^{3}$.

In the first strategy of "doing nothing", $\mathrm{C}_{\text {jcap }}(\mathrm{t})$ includes the costs of constructing 2 supply wells with pumping rates equal to $750 \mathrm{~m}^{3}$ each, plus the costs of pipelines which are estimated as $\$ 24,000$, in order to continuously supply the nearby village with water.

The probabilistic cost of failure with respect to the supply wells, $\mathrm{C}_{\mathrm{fjw}}(\mathrm{t})$, (see Appendix), reflecting the costs of finding and transferring water from elsewhere in cases that the supply wells will be found contaminated, is estimated as $\$ 160,000$ for each year.

The probabilistic cost of failure with respect to the aquifer, $\mathrm{C}_{\mathrm{fja}}(\mathrm{t})$, ( see Appendix), reflecting the pollution charges imposed by the water authority for each year of aquifer contamination, in this first step of the procedure is estimated as $\$ 40,000$. This value is assigned as usually happens by intuition or previous experience. This value is supposed to be rather moderate, high enough to act as incentive, and small enough to prevent social reaction against the water authority's policy.

All the above values of the various types of costs are based on the Greek experience.

\section{The risk-neutral case study}

First it is assumed that the polluter has a neutral perception regarding the risks associated with the decision-making process. This means that the utility functions $\gamma\left(\mathrm{C}_{\mathrm{fa}}\right)$ and $\gamma\left(\mathrm{C}_{\mathrm{fw}}\right)$ (see Appendix), are taken as equal to unity. This is the case that the polluter is a large industry or company, which can take its chances, as it has the economic means to afford, if necessary, high environmental risks.

The results obtained from the development of the risk-based decision model for the 7 in total alternative decision strategies, are presented in Table 2. The 2a, 3a, and 4a scenarios represent 6 years operation of the remedial plants in the $2^{\text {nd }}, 3^{\text {rd }}$ and 4 th alternative, respectively, while the $2 b, 3 b$, and $4 \mathrm{~b}$ scenarios represent 10 years of operation.

As the remedial plants in the $2^{\text {nd }}, 3^{\text {rd }}$ and $4^{\text {th }}$ alternatives become larger, the value of the capital and operational costs increase, while the value of the relevant risks decrease. As the increase in capital and operational costs is lower compared to the remarkable decrease of the high in the first scenario risks, the more the strategies become conservative the more they become attractive. Best solution occurs when 3 clean-up wells operate for 10 years, while other good solutions can be found when 4 wells operate for 10 and 6 years, respectively. This shows that although conservative policies correspond to safer solutions, this remark cannot be used generally, as the best solution in our case is connected with rather moderate scenarios, mainly as a result of the low environmental costs that have been taken into account.

As it can be seen, the "do nothing" scenario, according to which the contamination of the groundwater lasts for a long time period (as produced by the stochastic simulation model), leading therefore to high risks, is not found to be the worst alternative. Actually its total cost derived by 


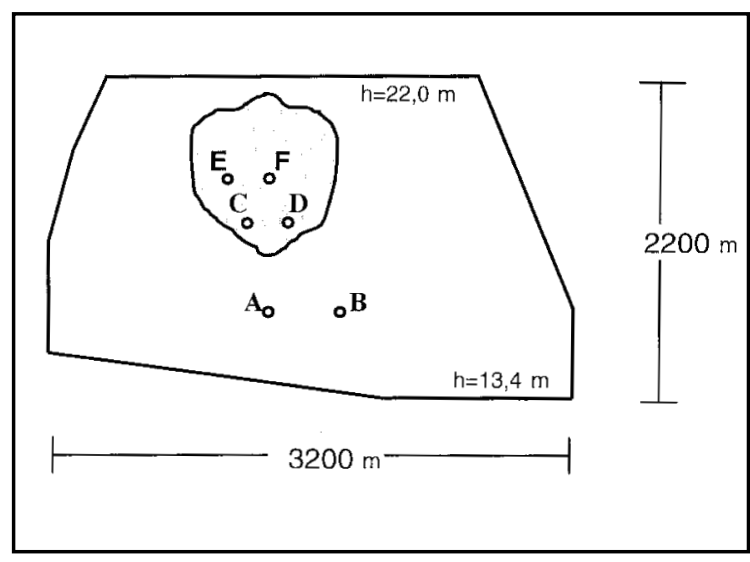

Figure 1. The aquifer under study with the contaminant plume, the water supply wells $\mathrm{A}$ and $\mathrm{B}$, and the clean-up wells C, D, E and F

the decision model is only $20 \%$ greater than the best alternative. This fact however makes this environmentally hostile scenario a competitive alternative policy. This is mainly because despite the high risks in terms of probabilities of failure, the related probabilistic costs were not high enough, under the risk-neutral attitude of the polluter. The pollution charges taken by intuition or by previous experience of the policy-makers as $\$ 40,000$ for each year of aquifer contamination, is now clear that was not high enough to act effectively as an incentive to the polluters to restore groundwater, as they are unable to make the least environmentally friendly solution to be the least attractive one.

\section{The risk averse case study}

Carrying out the management problem from the decision maker's point of view again, his risk- averse tendency can be taken into account by increasing the utility function $\gamma\left(C_{f}\right)$ (see Appendix). This is the case of a small industry or company, or even the case of an individual, who do not want to take their chances, as they cannot afford, if necessary, the high costs associated with the environmental risks. In the present approach the utility function is suggested to be described as follows:

For each year $t$ and for each alternative there are 3 possibilities. The first is the successful case, corresponding to the possibility of not finding contamination neither in the wells nor in the aquifer. The second case corresponds to the possibility that only the aquifer is found contaminated and not the supply wells, while the third case reflects the possibility that both the aquifer and the wells are contaminated. The probabilistic environmental costs for each of these possibilities are $\$ 0, \$ 40,000$ and $200,000,(\$ 160,000+\$ 40,000)$ respectively.

The polluter's risk-averse tendency will be expressed by giving $\gamma\left(\mathrm{C}_{\mathrm{f}}\right)$ its maximum value, $(\gamma=2)$, for the maximum probabilistic cost, corresponding to the $3^{\mathrm{rd}}$ possibility, where $\mathrm{C}_{\mathrm{f}}=$ $\$ 200,000$, its minimum value, $\gamma=1$, for the minimum probabilistic cost, corresponding to the $1^{\text {st }}$ possibility where $C_{f}=\$ 0$, and finally its mean value, $\gamma=1.5$, for the case of the moderate probabilistic cost of the $2^{\text {nd }}$ possibility, where $C_{f}=$ $\$ 40,000$. Based on these values, the utility function becomes as shown in Figure 2 .

The new results are presented in Table 3 . Following the increase of the risk term, the objective function takes higher values in each alternative, but mostly in the risky ones. Therefore the best solution now, that is $4 \mathrm{~b}$, is found among the most conservative alternatives. As for the "do

Table 2. Results in thousands of dollars, in a risk-neutral polluter's case.

Pollution charges have been taken as $\$ 40,000$ per year

\begin{tabular}{|c|c|c|c|c|c|}
\hline $\mathbf{j}$ & $\mathbf{C}_{\mathbf{j c a p}}$ & $\mathbf{C}_{\mathbf{j} \mathbf{p}}$ & $\mathbf{R}_{\mathbf{j a}}$ & $\mathbf{R}_{\mathbf{j w}}$ & $\boldsymbol{\Phi}_{\mathbf{j}}$ \\
\hline $\mathbf{1}$ & 146.7 & - & 337.1 & - & 483.8 \\
\hline $\mathbf{2 a}$ & 93.3 & 58.1 & 288.1 & 204.9 & 644.4 \\
\hline $\mathbf{2 b}$ & 93.3 & 81.9 & 243.2 & 107.8 & 526.2 \\
\hline $\mathbf{3 a}$ & 130.0 & 76.2 & 194.4 & 98.0 & 498.6 \\
\hline $\mathbf{3 b}$ & 130.0 & 107.5 & 131.3 & 36.9 & 405.7 \\
\hline $\mathbf{4 a}$ & 160.0 & 87.1 & 147.4 & 41.0 & 435.5 \\
\hline $\mathbf{4 b}$ & 160.0 & 122.9 & 108.3 & 21.3 & 412.5 \\
\hline
\end{tabular}




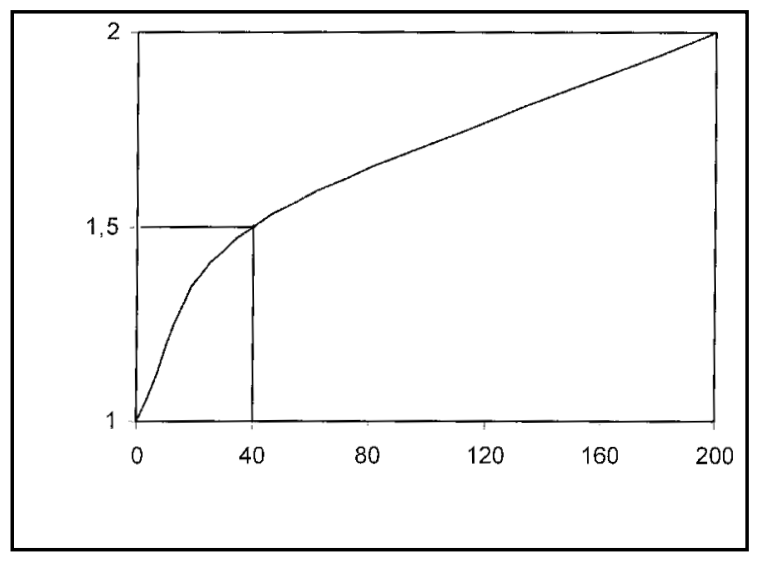

Figure 2. The utility function $\gamma\left(\mathrm{C}_{\mathrm{f}}\right)$ for each operation year in relation to the probabilistic costs, expressed in thousand of $\$$

nothing" strategy, it is now more expensive than in the risk-neutral case, where the value-difference between the two alternatives did not exceed $20 \%$. The risk-averse tendency increases this difference to $50 \%$, which means that it leads to less risky decisions and prevents from solutions unfriendly to the environment.

\section{Determining pollution charges. \\ The Water Authority's side}

From Tables 2 and 3, it can be easily derived that the rejection of the less environmentally friendly decisions, depends on the polluter's risk tendency. Given that risk aversion decreases with the increase of the company's magnitude and strength, it is very likely for a large industry to choose and follow the "do nothing" alternative. In order to overcome this problem, the local water authority must bring out the full environmental cost of water, which in our case is expressed by the pollution charges levied for each year that the aquifer is found contaminated.

The second probabilistic cost, which is the cost of failure with respect to the supply wells, $\mathrm{C}_{\mathrm{fw}}$, is assumed to have a constant value, in terms that its value is measurable and can be easily estimated, as it reflects opportunity costs, corresponding to the actual and probabilistic costs of meeting water supply demand of the nearby village.

The solution of giving an estimated value to pollution charges, $\mathrm{C}_{\mathrm{fe}}$, either by intuition or by previous experience, as in our case study, includes two major risks: either the value turns out to be too small to act as incentive to reject the "do nothing" alternative, as it happened in the first case of the risk-neutral polluter, or on the contrary, it can become an extremely high cost that cannot be easily accepted, as it acts speculatively rather than judiciously. These two risks impose the necessity of calculating pollution charges through an algorithm that takes into account the parameters of the specific problem, namely the actual and probabilistic costs, as well as the probabilities of failure of the evaluated policies, associated with the uncertainties of the design.

The suggestion of this paper is that the estimation of the pollution charges should be related to the risk-based objective function, corresponding to the two extreme alternatives: the least environmentally friendly, i.e. the "do nothing" on one hand, $\left(\Phi_{1}\right)$, and the most conservative in terms of environmental risks on the other, $\left(\Phi_{4 \mathrm{~b}}\right)$, reflecting the lowest $(0 \%)$, and the highest $(99 \%)$, probabilities of aquifer rehabilitation, respectively.

Given pollution charges, $\mathrm{C}_{\mathrm{fe}}$, a value that leads

Table 3. Results in thousands of dollars, in a risk-averse polluter's case.

Pollution charges have been taken as $\$ 40,000$ per year

\begin{tabular}{|c|c|c|c|c|}
\hline $\mathbf{j}$ & $\mathbf{C}_{\text {jcap }}$ & $\mathbf{C}_{\mathbf{j o p}}$ & $\mathbf{R}=\mathbf{R}_{\mathbf{j a}}+\mathbf{R}_{\mathbf{j w}}$ & $\boldsymbol{\Phi}_{\mathbf{j}}$ \\
\hline $\mathbf{1}$ & 146.7 & - & 503.7 & 650.4 \\
\hline $\mathbf{2 a}$ & 93.3 & 58.1 & 725.6 & 877.0 \\
\hline $\mathbf{2 b}$ & 93.3 & 81.9 & 467.4 & 642.6 \\
\hline $\mathbf{3 a}$ & 130.0 & 76.2 & 380.1 & 586.3 \\
\hline $\mathbf{3 b}$ & 130.0 & 107.5 & 233.8 & 471.3 \\
\hline $\mathbf{4 a}$ & 160.0 & 87.1 & 233.6 & 480.7 \\
\hline $\mathbf{4 b}$ & 160.0 & 122.9 & 151.2 & 434.1 \\
\hline
\end{tabular}


to a relation of the form (see Appendix):

$$
\Phi_{1}=\mathrm{k} \Phi_{4 \mathrm{~b}}
$$

it is up to the policy-maker then to define $\mathrm{k}$, so that the "do nothing" alternative will become as less attractive as it is desired. Of course, it is suggested that the "worst" case of risk-neutral tendency of the polluter should be assumed for the application of the decision model and the estimation of the two extreme values of the objective function.

As a case study, under the condition of risk-neutral attitude of the polluter, in order to make $\Phi_{1}$ $50 \%$ higher than $\Phi_{4 \mathrm{~b}}$, which corresponds to a value of $\mathrm{k}$ equal to 1.5 , the pollution charge, $\mathrm{C}_{\mathrm{fe}}$, must become $\$ 57,000$. The results obtained by the application of the decision model for such a policy are presented in Table 4.

As it can be seen, the economic policy followed by the water authority is now effective indeed, as the more the alternative is environmentally friendly, the more it becomes attractive to the decision-makers. The most attractive alternative has become now the environmentally sustainable policy of safely restoring the aquifer, corresponding to a probability of success of $99 \%$, while the extremely environmentally risky alternative of "doing nothing", corresponding to a $100 \%$ probability of failure of restoring the aquifer, became one of the two worst policies. The "do nothing" scenario has become exactly as the water authority desired, 1.5 times more expensive than the "safe" one. This economic policy imposed by the water authority is clear now that it can act as an effective incentive to the polluters, as it can guarantee both, the selection of the more environmentally friendly, and on the contrary the rejection of the more environmentally risky policy, even in cases that the polluters may have a risk-neutral tendency.

\section{CONCLUSIONS}

The present work offered a tool for quantifying approaches to water resources management. The risk-based decision analysis framework presented, can be used as a water policy tool in the design of economic incentive instruments, under conditions of uncertainty. Pollution charges can now be determined on a risk-cost-benefit basis in such a way that they can guarantee either the promotion of the more environmentally friendly, or the rejection of the more environmentally risky water policy. Pollution charges are now becoming effective economic incentive instruments in the direction of forcing polluters to restore water resources rather, instead of simply paying penalties for the environmental degradation they caused.

Pollution charges calculated with the use of the risk-based decision model, were related on the one hand to the full-cost price of water, including direct, opportunity, and environmental actual and probabilistic costs of water, and on the other to the risks of failure associated with the uncertainties of the design. The methodology effectively determines economic incentives that can lead to sustainable water policy decisions, as the pollution charging system emerging in such a way that induces conservation, protection and restoration of water resources.

The role of the risk attitude of the various kinds of decision makers was explored, through the study of the utility function of the risk-based decision model. A new method of estimating the

Table 4. Results of the decision model for the case of a risk-neutral polluter, with pollution charges equal to $\$ 57,000$ per year (in thousands of dollars)

\begin{tabular}{|c|c|c|c|c|c|}
\hline $\mathbf{j}$ & $\mathbf{C}_{\mathbf{j c a p}}$ & $\mathbf{C}_{\mathbf{j o p}}$ & $\mathbf{R}_{\mathbf{j a}}$ & $\mathbf{R}_{\mathbf{j w}}$ & $\boldsymbol{\Phi}_{\mathbf{j}}$ \\
\hline $\mathbf{1}$ & 146.7 & - & 573.1 & - & 719.8 \\
\hline $\mathbf{2 a}$ & 93.3 & 58.1 & 489.7 & 204.9 & 846.0 \\
\hline $\mathbf{2 b}$ & 93.3 & 81.9 & 413.4 & 107.8 & 696.4 \\
\hline $\mathbf{3 a}$ & 130.0 & 76.2 & 330.4 & 98.0 & 634.6 \\
\hline $\mathbf{3 b}$ & 130.0 & 107.5 & 223.2 & 36.9 & 497.6 \\
\hline $\mathbf{4 a}$ & 160.0 & 87.1 & 250.6 & 41.0 & 538.7 \\
\hline $\mathbf{4 b}$ & 160.0 & 122.9 & 184.2 & 21.3 & 488.4 \\
\hline
\end{tabular}


utility function in cases of risk-averse tendency was applied, and the risk-averse case study was appropriately correlated with the risk-neutral one, leading to useful conclusions concerning the role of this function in the decision-making process.

The development of the risk-based decision model proposed in this study by the decision maker, will lead him eventually to the determination of such pollution charges that the final cost of the extreme, environmentally hostile alternative will turn out to be an amount multiple of the fully restoration scheme's cost. Thus, defining the desired relation between the two environmentally extreme alternative policies, the decision maker can give the pollution charges an incentive character in order to force polluters to select and follow the most sustainable of all alternative policies. In other words, the decision maker can shift "the Polluter Pays" principle to "the Polluter Restores" one.

\section{APPENDIX \\ THE SIMULATION MODEL}

The Governing Equations

The governing equation for the two-dimensional steady-state flow in a horizontal confined aquifer is:

$$
\frac{\partial T_{i j}}{\partial x_{i}}+\frac{\partial h}{\partial x_{j}}=W
$$$$
i, j=1,2
$$

where $\mathrm{h}$ is the hydraulic head, $\mathrm{T}_{\mathrm{ij}}$ is the transmissivity tensor $\left(\mathrm{T}_{\mathrm{ij}}=\mathrm{bK}_{\mathrm{ij}}\right.$, where $\mathrm{b}$ is the aquifer thickness and $\mathrm{K}_{\mathrm{ij}}$ is the hydraulic conductivity tensor), $\mathrm{W}$ is the source-sink term and $\mathrm{x}_{\mathrm{i}}, \mathrm{x}_{\mathrm{j}}$ are the spatial coordinates.

The governing equation for reactive single species solute transport in a two-dimensional horizontal aquifer is:

$$
\begin{aligned}
& R \frac{\partial(b c)}{\partial t}=\frac{\partial}{\partial x_{i}}\left(b \cdot D_{i j} \cdot \frac{\partial c}{\partial x_{j}}\right)- \\
& -\frac{\partial}{\partial x_{i}}\left(b c v_{j}\right)-\frac{c^{\prime} W}{n} \quad i, j=1,2
\end{aligned}
$$

where $\mathrm{c}$ is the solute concentration, $\mathrm{R}$ is the retardation factor, $D_{i j}$ the hydrodynamic dispersion tensor, $\mathrm{v}_{\mathrm{i}}$ is the groundwater velocity vector, $\mathrm{c}^{\prime}$ is the solute concentration in fluid source/sink, $n$ is the effective porosity and $t$ is time.

In order to solve the above equations $\mathrm{A} 1$ and A2, the USGS MOC (Method Of Characteristics) model of two-dimensional solute transport and dispersion in groundwater (Konikow and Bredehoeft, 1978) was chosen. This well-known model is a very efficient numerical code with a structure allowing for reliable simulation of realworld problems in both the deterministic and stochastic contexts.

The pollutant's (TCE) behavior is described in the transport equation by the linear sorption term, having a retardation factor $\mathrm{R}_{\mathrm{f}}=1.9$ (Y. Mylopoulos et al., 1994).

\section{The stochastic simulation model}

Making decisions under uncertainty always incorporates the risk term, as uncertainty always affects the efficiency and the effectiveness of the designed policies, involving in the decision-making process the concept of the probability of failure. In the present study it is assumed that the uncertainty as to the hydraulic conductivity is the sole source for risky decisions, and, therefore, the stochastic approach is focused upon the spatial distribution of this parameter. The quantification of risk has traditionally been handled by employing a stochastic model of groundwater flow and solute transport. It is generally accepted that the Monte Carlo technique is very suitable in doing this (Massmann and Freeze, 1987a,b; Freeze et al., 1990; Massmann et al., 1991; Mylopoulos et al., 1994; Latinopoulos et al., 1997).

Within the context of the stochastic approach, the true spatial distribution of the hydraulic conductivity is considered to be a single realization of the spatially random field of this heterogeneous variable. By invoking the assumptions of stationarity and ergodicity, the moments of the random field can be inferred using information and/or in situ measurements form the single realization, i.e. the spatial distribution of the hydraulic conductivity of the aquifer under study (Gelhar, 1986). By restricting stationarity to the first two moments - a fact that guarantees also a stationary covariance the mean of the random field is constant in space and the covariance between two locations is a function of their separation vector only. As it is widely accepted (Hoeksema and Kitanidis, 1985), the distribution of hydraulic conductivity can be 
assumed to be log-normal. After all the above, the random log-hydraulic conductivity field is statistically characterized by three parameters, namely $\mu_{\mathrm{Y}}, \sigma^{2} \mathrm{Y}$ and $\lambda_{\mathrm{Y}}$, that is the mean, the covariance and the correlation length, respectively. In the present application an isotropic exponential covariance (Hoeksema and Kitanidis, 1985) is assumed:

$$
\operatorname{Cov}\left[Y_{i}, Y_{j}\right]=\sigma_{Y}^{2} \exp \left\{-\left|\Delta x_{i j}\right| / \lambda_{Y}\right\}
$$

where $\mathrm{Y}_{\mathrm{i}}-\log \mathrm{K}_{\mathrm{i}}$ is the natural $\operatorname{logarithm}$ of the hydraulic conductivity at any point $\mathrm{x}_{\mathrm{i}}, \mathrm{Cov}[\cdot]$ is the covariance of the random variable, and $\left|\Delta \mathrm{x}_{\mathrm{ij}}\right|$ is the distance between two arbitrary points $\mathrm{x}_{\mathrm{i}}$ and $\mathrm{x}_{\mathrm{j}}$ in the field.

The particular Monte Carlo procedure used in the present probabilistic study of groundwater flow and contaminant transport consists of the following steps:

a. Given the three statistical parameters of the stationary, correlated, 2-D random field, Yi, a number of realizations is generated by applying the method of turning bands (Mantoglou and Wilson, 1982).

b. Each hydraulic conductivity realization is used as input data to the MOC model together with the set of the rest of parameters, boundary conditions, etc, which are considered deterministic in all simulations.

c. Performing a number of simulations - equal to the number of the generated realizations with the MOC model, the frequency distribution of specific output variables can be obtained. Although in most practical problems the variable under study is the contaminant concentration, in our case it is the frequency distribution of the duration of contaminant episodes, which is used to quantify the level of risk that is associated with the hydrogeologic uncertainty.

The random hydraulic conductivity field is assumed to follow log-normal distribution with expected mean value of hydraulic conductivity $\mathrm{K}_{\mathrm{m}}$ $=2 \times 10^{-4} \mathrm{~m} / \mathrm{s}$, standard deviation $\sigma_{\mathrm{k}}=2 \times 10^{-4} \mathrm{~m} / \mathrm{s}$ and correlation length $\lambda=200 \mathrm{~m}$. To perform the numerical simulations with the MOC model, the aquifer is descretized into 693 square cells, with a discretization of $100 \times 100$.
Using Monte Carlo analysis, a wide range of realisations of the random field of hydraulic conductivity is produced (300 for this case study), resulting in an equal number of relevant probable contamination episodes.

\section{THE RISK-BASED DECISION MODEL}

In the context of the decision analysis methodology described in this paper, a risk-cost-benefit objective function is employed for the evaluation and comparison of alternative design strategies. As the benefits in our case are essentially zero, only the costs and risks of different strategies are incorporated into the function. Thus, for each alternative the objective function $\Phi_{j}(\mathrm{t})$ can be written as:

$$
\Phi_{j}(t)=\sum{ }_{t=0}^{T}\left[C_{j c a p}(t)+C_{j o p}(t)+R_{j}(t)\right] /(1+i)^{t}
$$

where:

$\mathrm{j}$ : the alternative

$\mathrm{T}$ : the time horizon ( 35 years in our case)

i: the discount rate taking a value of $10 \%$ for all cases

$\mathrm{C}_{\text {jcap }}(\mathrm{t})$ : the actual capital cost of constructing the remediation wells in $t$ year of $\mathrm{j}$ alternative,

$\mathrm{C}_{\text {jop }}(\mathrm{t})$ : the actual annual operation costs of the clean-up wells,

$\mathrm{R}_{\mathrm{j}}(\mathrm{t})$ : the annual risk term, estimated as:

$$
R_{j}(t)=R_{j a}(t)+R_{j w}(t)
$$

where $\mathrm{R}_{\mathrm{ja}}(\mathrm{t})$ and $\mathrm{R}_{\mathrm{jw}}(\mathrm{t})$ are the two types of risk, estimated as:

$$
\begin{aligned}
& \mathrm{R}_{\mathrm{ja}}(\mathrm{t})=\mathrm{P}_{\mathrm{fja}}(\mathrm{t}) \cdot \mathrm{C}_{\mathrm{fja}}(\mathrm{t}) \cdot \gamma\left(\mathrm{C}_{\mathrm{fa}}\right) \\
& \mathrm{R}_{\mathrm{jw}}(\mathrm{t})=\mathrm{P}_{\mathrm{fjw}}(\mathrm{t}) \cdot \mathrm{C}_{\mathrm{fjw}}(\mathrm{t}) \cdot \gamma\left(\mathrm{C}_{\mathrm{fw}}\right)
\end{aligned}
$$

where:

$P_{f j a}(t)$ : the probability of failure with respect to the aquifer in the $t$ year,

$\mathrm{P}_{\mathrm{fjw}}(\mathrm{t})$ : the probability of failure with respect to the supply wells in the $t$ year,

$\mathrm{C}_{\mathrm{fja}}(\mathrm{t})$ : the probabilistic cost of failure with respect to the aquifer in $t$ year, reflecting the pollution charges imposed by 
the water authority for each year of aquifer contamination,

$\mathrm{C}_{\mathrm{fjw}}(\mathrm{t})$ : the probabilistic cost of failure with respect to the supply wells in $t$ year, reflecting the costs of meeting the water supply demands for each year and

$\gamma\left(\mathrm{C}_{\mathrm{fa}}\right)$ and $\gamma\left(\mathrm{C}_{\mathrm{fw}}\right)$ : the utility functions for the two types of risk, reflecting the risk perception of the decision maker $(1$ for risk-neutral and $>1$ for risk-averse attitudes).

\section{REFERENCES}

Covello, V. (1987). Decision Analysis and Risk Management Decision Making: Issues and Methods. Risk Analysis 7, 131-139.

Freeze, A., Massmann J., Smith L., Sperling T. and James B., (1990). Hydrogeological Decision Analysis 1. A Framework Ground Water, 28 (5), 738-766.

Gelhar, L. W. (1986). Stochastic subsurface hydrology: From theory to applications. Water Resources Research 22, 135S-145S

Hoeksema, R. J., and Kitanidis P. K., (1985). Analysis of the spatial structure of properties of selected aquifers. Water Resources Research 21, 563-572.

Jonch-Clausen, T. (1994) The freshwater problem and Rio: Background, process and key issues. Putting Dublin/Agenda 21 into practice. Lessons and new approaches in Water and Land Management. Editors Lundqvist J., Jonch-Clausen, T., Special Session at VIIIth IWRA World Congress, Cairo, Egypt, pp 5-15.

Konikow, L.F., and Bredehoeft J.D., (1978). Computer model of two-dimensional solute transport and dispersion in ground water. Techn. Water Resour. Invest., U.S. Geol. Surv., 7(2).

Latinopoulos, P., Mylopoulos N. and Mylopoulos Y., (1997). Risk-Based Decision Analysis in the Design of Water Supply Projects. Water Resources Management, 11, 263-281.

Mantoglou, A., and Wilson, J. L., (1982). The turning bands method for simulation of random fields using line generation by a spectral method. Water Resources Research 18, 1379-1394.

Massmann, J., Freeze A., (1987). Groundwater contamination from waste management sites: The interaction between risk-based engineering and regulatory policy. 1. Methodology. Water Resources Research 23, 351-367.

Massmann, J., Freeze A., (1987). Groundwater contamination from waste management sites: The interaction between risk-based engineering and regulatory policy. 2. Results. Water Resources Research 23, 368-380.

Massmann, J., Freeze A., Smith L., Sperling T., and James B., (1991). Hydrogeological Decision Analysis: 2.Applications to Ground - Water Contamination. Ground Water, 29, 536-548.

Mylopoulos Y. A. (1996). Sustainable Water Management in Greece. A Dream or a Vision? Rational and Sustainable Development of Water Resources, No 6, Vol. II, Collection Environnement de l' Universite de Montreal, Montreal, Canada, pp. 652 - 660.

Mylopoulos Y., Mylopoulos N., and Latinopoulos P., (1994). Risk-based decision modelling in the engineering design of groundwater pollution problems. Advances in Water Resources Technology and Management, G.Tsakiris \& M. A. Santos (Eds.), Balkema, Rotterdam, pp. 269-274.

Mylopoulos, Y. and Kolokytha E., (1996). Economic incentive instruments in sustainable environmental management. The water resources case. Proc. of International Conference: Restoration and Protection of the Environment III. Technical University of Crete, Greece, pp. 600 - 608.

Sarokin, D. and Schulkin J., (1993). The necessity of Environmental Economics. Journal of Environmental Management 38, 259-280.

Winpenny, J. (1994) Managing Water as an Economic Resource, Routledge, New York.

World Commission on Environment and Development, 1987, Our common future. Oxford University Press, London, ON. 